pertinent to managing marine resources. There will be hotspots of change, such as sites of marine heat waves ${ }^{7}$, or places where regional warming exceeds the global average, such as the western Antarctic Peninsula. Yet limits to the resolution and boundary conditions of global circulation models make it hard to represent changes in coastal regions. Regional projections from global climate models rarely agree and they exclude other human stressors such as fishing pressure and pollution.

The IPCC special report needs to tease apart how combinations of global, regional and local stressors will increase pressures on marine ecosystems and services in particular places. This would help local managers to buy time to mitigate the combined effects of multiple factors. For example, managing the run-off of sediment, nutrients and contaminants into coastal waters near Australia's Great Barrier Reef (see, for example, go.nature.com/2ex5leq) should give corals respite from devastating outbreaks of crownof-thorns starfish (Acanthaster planci) that can add to the regular stress of bleaching (expelling algae under warmer conditions) during El Niño events.

Developing regional and local marine policies requires better understanding of governance mechanisms, management and trade practices too. The IPCC report should include examples of using local know-how to underpin policies from across the three IPCC working groups (such as the Great Barrier Reef example). The focus is still too much on physical signals of climate change ${ }^{8}$. Interdisciplinary studies need to be done on the legal and economic frameworks that support regional resilience - social and ecological.

\section{LIFE STORY}

A final challenge for ocean scientists is to describe how marine life in diverse ecosystems will respond to the complex matrix of anthropogenic change ${ }^{8}$. Biologists do not understand fully the cumulative responses of the key components of ecosystems to a changing climate. What we have now are snapshots of how a few species within coastal food webs react to more acidic or warmer conditions.

Organisms may react in a nonlinear way ${ }^{1}$. If a species is already living in the warmest conditions it can handle, any further temperature rise will have lethal consequences, whereas a cooling would improve fitness. For example, many species of plankton in the tropical ocean are thought to be close their upper temperature limits ${ }^{8}$.

Experiments need to reflect the wider range of changes to local ocean conditions that will occur in the coming years and decades. And researchers need to consider how extremes and fluctuating conditions

\section{READING THE WAVES}

Water temperatures fluctuate naturally around mean conditions as well as regionally. Year-to-year or decadal variations are currently hard to distinguish from global warming trends (A). Different places will encounter varying marine and climate pressures at different times. Data from the Pacific Ocean, for example, reveal many rapid changes in local sea temperatures (B)
Conceptual projection of how ocean temperature might vary in coming decades

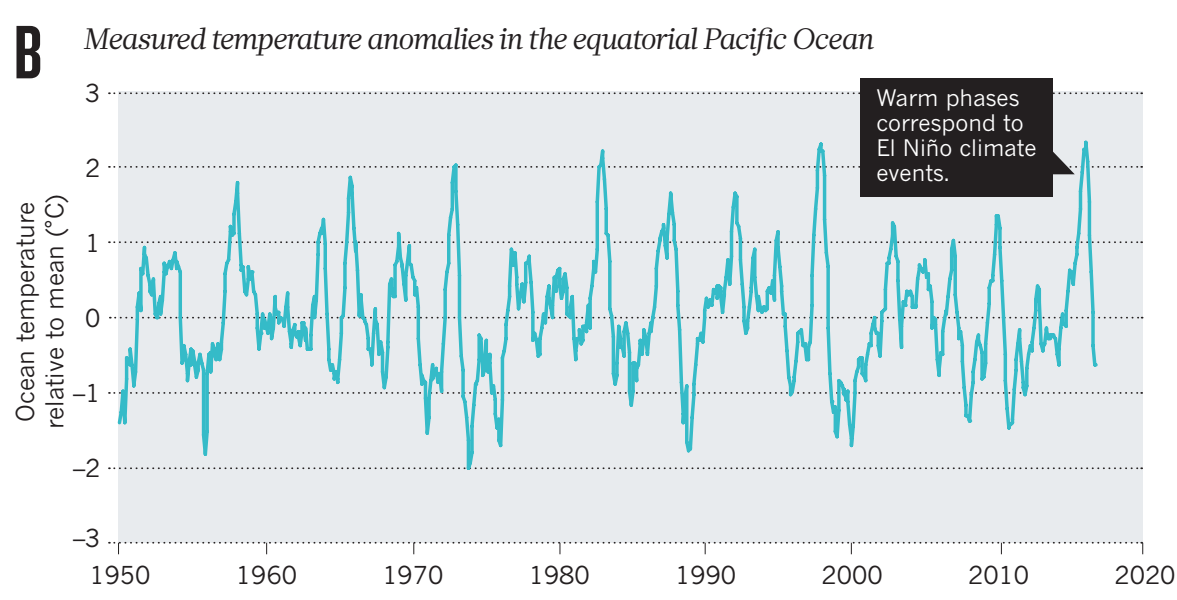

affect physiologies. For example El Niño events may increase the mortalities of some species in the Pacific by adding to anthropogenic warming; whereas the cooler La Niña phase of the cycle would offer respite. How these processes balance out, if the periods of relief are long enough to allow recovery, and which species will be most affected are all open questions. This uncertainty is fundamental to our ability to predict the societal impacts of these ecological changes.

Places where warming is now above the global average are natural laboratories ${ }^{9}$. They include marine sanctuaries such as the Galapagos Islands and areas where humans rely heavily on ocean resources, such as southeast Asia and western Africa'. Environmental impact assessments in these places have revealed that some ecological changes, such as the loss of Australian kelp, are irreversible even if the physical environment returns to average conditions ${ }^{7}$. During heat waves, for instance, warmer water species migrate into colder water habitats, where they may replace the endemic species. Extreme events therefore can push ecosystems past tipping points.

Describing the oceans' variability will ensure that the IPCC report builds a bridge to the sustainable development goals. This must be reflected in the choices made in December's meeting of ocean experts.

Daniela Schmidt is professor of palaeobiology, School of Earth Sciences, University of Bristol, UK. Philip W. Boyd is a marine biogeochemist, Institute for Marine and Antarctic Studies, University of Tasmania, Hobart, Australia. e-mail:d.schmidt@bristol.ac.uk

1. Pörtner, H. O. et al. in Climate Change 2014: Impacts, Adaptation, and Vulnerability. Part A: Global and Sectoral Aspects. Contribution of Working Group II to the Fifth Assessment Report of the Intergovernmental Panel on Climate Change (eds C. B. Field et al.) Ch. 6, 411-484 (Cambridge Univ. Press, 2014).

2. Hoegh-Guldberg, O. et al. in Climate Change 2014: Impacts, Adaptation, and Vulnerability. Part B: Regional Aspects. Contribution of Working Group /I to the Fifth Assessment Report of the Intergovernmental Panel of Climate Change (eds V. R. Barros et al.) Ch. 30, 1655-1731 (Cambridge Univ. Press, 2014).

3. Mora, C. et al. Nature 502, 183-187 (2013).

4. Hawkins, E. et al. Nature 511, E3-E5 (2014).

5. Xie, S.-P. Nature Clim. Change 6, 345-346 (2016).

6. IPCC. Managing the Risks of Extreme Events and Disasters to Advance Climate Change Adaptation. A Special Report of Working Groups I and II of the Intergovernmental Panel on Climate Change 582 (Cambridge Univ. Press, 2012).

7. Wernberg, T. et al. Science 353, 169-172 (2016).

8. Boyd, P. W. et al. Glob. Change Biol. 22, 2633-2650 (2016).

9. Hobday, A. J. \& Pecl, G. T. Rev. Fish Biol. Fisher. 24, 415-425 (2014). 